\title{
Early Ontogenetic Diet in Gray Wolves, Canis lupus, of Coastal British Columbia
}

\author{
Heather M. Bryan ${ }^{1}$, Chris T. Darimont ${ }^{1,2,4}$, Thomas E. Reimchen ${ }^{1}$, and Paul C. PaqueT ${ }^{2,3}$ \\ ${ }^{1}$ Department of Biology, University of Victoria, P.O. Box 3020, Station CSC, Victoria, British Columbia V8W 3N5 Canada \\ ${ }^{2}$ Raincoast Conservation Society, P.O. Box 26, Bella Bella, British Columbia V0T 1B0 Canada \\ ${ }^{3}$ Faculty of Environmental Design, University of Calgary, Calgary, Alberta T2N 1N4 Canada \\ ${ }^{4}$ Corresponding author: cdarimon@uvic.ca
}

Bryan, Heather M., Chris T. Darimont, Thomas E. Reimchen, and Paul C. Paquet. 2006. Early ontogenetic diet in Gray Wolves, Canis lupus, of coastal British Columbia. Canadian Field-Naturalist 120(1): 61-66.

Within populations, different age classes often consume dissimilar resources, and provisioning of juveniles by adults is one mechanism by which this can occur. Although the diet of Gray Wolves (Canis lupus) has been studied extensively, the diet of pups is largely unknown. We examined faeces deposited by altricial pups and adult providers during the first two months following birth at two den sites over two years on the central coast of British Columbia, Canada. Pups and adult wolves consumed similar species, and Black-tailed Deer (Odocoileus hemionus) constituted most of the diet for both age groups. Pup and adult diet, however, diverged. Specifically, adult deer occurred significantly less frequently in the diet of pups than in the diet of adult wolves, which suggests that adults selectively provisioned pups. We speculate that this may relate to adaptive strategies of adult wolves to provide their offspring with food of optimal nutritional value or reduced parasitic burden, and/or logistic factors associated with provisioning such as prey transportability and availability.

Key Words: Gray Wolf, Canis lupus, Sitka Black-tailed Deer, Odocoileus hemionus, provisioning, pups, diet, British Columbia.

Different age classes within a species often consume dissimilar resources, increasing population niche width and decreasing intraspecific competition (Polis 1984; Bolnick et al. 2003). Provisioning of young by adults is one mechanism whereby differences in diet between young and adults may occur (Markman et al. 2002). Foragers that select foods to optimize growth and development of their offspring may have a selective advantage over those that provision their young opportunistically (Krebs and Avery 1984; Wright et al. 1998). Providers may select resources that are easy to transport (Molsher et al . 2000) or that have nutritional qualities important for developing juveniles (Krebs and Avery 1984). Furthermore, providers may alter their behaviour while rearing young to reduce exposure of their offspring to parasites (Christe et al. 1994; Merilä and Allander 1995; Tripet et al. 2002).

Young Gray Wolves (Canis lupus) rely predominantly on food killed and delivered by closely related adult providers for many months (Paquet and Carbyn 2003). Although diets of adult wolves have been studied extensively, the diet of juvenile wolves has not been well documented in any system (Paquet and Carbyn 2003).

Wolves of coastal British Columbia (BC) have a potential niche that includes up to 15 mammal species (Darimont and Paquet 2000*, 2002; Darimont et al. 2004), which likely differ in transportability, nutritional characteristics, and parasite load. Herein, we investigated potential age class differences in diet by examining faeces of pups and adults deposited at den sites within the first two months following birth for two social groups over two breeding seasons. Our objectives were to describe the diet of adult and juvenile wolves during the denning season and examine whether the diet of pups differed from that of adults. Given the ubiquity of evidence from a variety of other systems, we predicted that adult wolves would selectively provision food resources to developing pups.

\section{Study Area}

We collected faeces from two home sites (i.e., reproductive areas) on the central coast of British Columbia in July of 2001 and 2002. The study area has been described well elsewhere (Darimont and Paquet 2002; Darimont et al. 2004). One site was located on Chatfield Island (area: $48 \mathrm{~km}^{2}$; distance from mainland: $1 \mathrm{~km}$; centre island location: $52^{\circ} 16^{\prime} \mathrm{N}, 128^{\circ} 05^{\prime} \mathrm{W}$ ) and the other on Yeo Island $\left(98 \mathrm{~km}^{2} ; 0.25 \mathrm{~km} ; 52^{\circ} 21^{\prime} \mathrm{N}\right.$, $128^{\circ} 08^{\prime} \mathrm{W}$ ). Both sites were $<100 \mathrm{~m}$ ASL (above sea level). During the study, social groups were composed of 3-7 pups and 3-8 adults. Potential prey species include Sitka Black-tailed Deer (Odocoileus hemionus sitkensis), mustelids, ursids, birds, rodents, fish, and marine mammals and invertebrates (Darimont and Paquet 2000*, Darimont et al. 2004).

\section{Materials and Methods}

Scat collection and analysis

Both sites were on or within $50 \mathrm{~m}$ from transects monitored for faeces during spring (April/May) before arrival of wolves or birth of pups, and summer (July) after wolves had left the areas. Thus, we are confident that faeces collected during July represent resources 
acquired during May and June, at which time pups were approximately 2-8 weeks old. This period also corresponds to the birth pulse of many prey in the area, including deer (Shackleton 1999).

In all cases, wolves had moved to another site by July, so we sampled all or most faeces that surrounded the abandoned sites (within $\sim 100 \mathrm{~m}$ ). Based on diameter, we subjectively classified faeces $(n=479)$ as those deposited by pups or adults. In July, pup faeces are easy to distinguish from those of adults and there is no overlap in diameter (Weaver and Fritts 1979). The few faeces that were mostly liquid or suggestive of severe weathering (i.e., amorphous shape or irregular surface; $\mathrm{n} \sim 20$ ), which we felt could not be accurately classified, were discarded.

Faeces were autoclaved, washed, and dried so that only macroscopic components such as hair, bone, teeth, and hooves remained (Cuicci et al. 1996). To identify mammalian prey items, we examined the entire sample with the naked eye to detect hair clumps that differed in colour, size and/or texture from others, and other clues such as teeth, claws and hooves. Subsequently, we microscopically examined five sub-samples, randomly selected via a grid system in the sample tray, which typically contained five to 10 hairs each. We identified species by comparing with a reference hair collection, as well as cuticular scale imprints using dissecting and compound microscopes and dichotomous keys (Mayer 1952; Adorjan and Kolenasky 1969). We differentiated between adult deer and fawn hair using a combination of diameter and colour characteristics (Scott and Shackleton 1979). Birds and invertebrates were identified by feathers, claws, shell fragments, and cuticles and were scored as present or absent. Using an $8 \times 10$ grid of 1 -cm squares, we estimated the percentage of prey species in each faeces.

All faeces were analyzed by one observer (HB) to eliminate inter-observer bias (Spaulding et al. 2000). Before faecal analysis, we tested observer accuracy with a reference collection and scored $92 \%$ (23 out of 25 correct). Following identification of prey remains, we also assessed precision and scored 100\% (25/25) on classification of taxa. Finally, we investigated our precision in assessing adult/fawn categorization. We classified 77\% (17/22) correctly. This bias, however, was directional: we scored five adults incorrectly as fawns.

\section{Data analysis}

We used two indices in analysis. Percentage of whole scat equivalents (pWSE) is the mean percentage of each prey species found per faeces (Angerbjörn et al. 1999; Elmhagen et al. 2002). For example, two faeces containing deer and seal in percentages of 40,60 and 60,40 respectively, would have pWSE of 50 for both prey species. Percent occurrence per item $(\mathrm{O} / \mathrm{I})$ is the number of occurrences of each prey species divided by the total number of items identified, where an item is defined as an occurrence of a prey species in an individual faeces (Theberge et al. 1978).

We used log-linear analysis on pWSE data to test for differences in diet between pups and adult wolves while simultaneously assessing influences of years and sites. We excluded birds and invertebrates from this analysis because conversion to pWSE was not possible on presence/absence data. These items occurred infrequently and were never found alone in faeces. In this log-linear analysis, we also combined non-deer items into an "other" category due to infrequent occurrence (see Results).

To measure dietary breadth of both age classes, we used Levin's Measure, standardized on a scale from 0 to 1 (Hurlbert 1978; Krebs 1999; Elmhagen et al. 2002). Levin's measure of dietary breadth, $B_{A}$, is calculated using pWSE data as follows:

$$
B_{A}=\left[\frac{1}{\sum p_{i}^{2}}-1\right] /(n-1)
$$

where $p_{i}$ is the proportion of resource $i$ in a diet consisting of $n$ resources.

We also calculated dietary overlap between age classes using Schoener's measure $\left(p_{j k}\right.$; Shoener 1970) and Horn's index $\left(R_{o}\right.$; Horn 1966). Both calculations indicate food-niche overlap between populations $j$ and $k$, where $p_{i j}$ and $p_{i k}$ are the proportions of resource $i$ in diets, and $n$ is the number of available resources. Although Shoener's measure is frequently used and therefore comparable to other literature, Horn's index is less biased under changing numbers of resources, sample size, and resource evenness (Krebs 1999). Calculations were performed on pWSE data.

$$
\mathrm{p}_{\mathrm{jk}}=\left[\sum^{\mathrm{n}}\left(\text { minimum } \mathrm{p}_{\mathrm{ik}}, \mathrm{p}_{\mathrm{ij}}\right)\right] 100
$$

$$
\mathrm{R}_{0}=\frac{\sum\left(\mathrm{p}_{i j}+\mathrm{p}_{\mathrm{ik}}\right) \log \left(\mathrm{p}_{\mathrm{ij}}+\mathrm{p}_{\mathrm{ik}}\right)-\sum \mathrm{p}_{\mathrm{ij}} \log \mathrm{p}_{\mathrm{ij}}-\sum \mathrm{p}_{\mathrm{ik}} \log \mathrm{p}_{\mathrm{ik}}}{2 \log ^{2}}
$$

\section{Results}

Pup and adult wolves consumed a breadth of resources; however, Sitka Black-tailed Deer constituted most of the diet for both age classes (Table 1). Deer represented 54.6 to $100 \%$ of whole scat equivalents, depending on site and year, and accounted for 50.0 to $98.4 \%$ of all prey items (Table 1). After deer, Harbour Seal (Phoca vitulina), invertebrates, and birds were the most common prey items, whereas Beaver (Castor canadensis), Short-tailed Weasel (Mustela ermina), Mink (Mustela vison), River Otter (Lutra canadensis), Marten (Martes americana), and Fisher (Martes pennati) occurred infrequently in the diets of pups and adult wolves (Table 1). Pups and adults had 


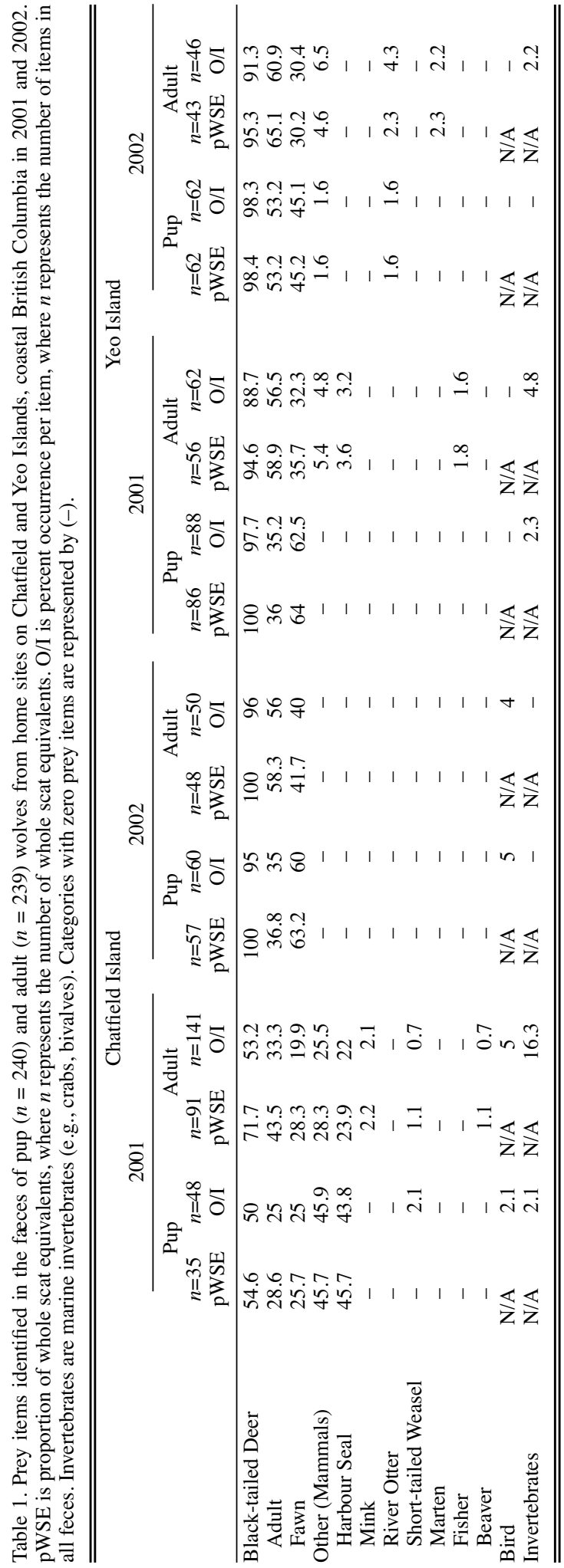

similar dietary breadths (Table 2). Average percent dietary overlap between pup and adult wolves was 79\%, whereas Horn's index showed a considerably higher average dietary overlap of 0.96 (Table 2).

A major difference between pup and adult diet was the proportion of different age classes of deer consumed. Pups consumed a lower proportion of adult deer and a higher proportion of fawn compared with adults (Partial $\chi^{2}=17.77, \mathrm{df}=2, P<0.001$; Table 1 ). The magnitude of this difference varied across years and locations (association between location, age class of wolf, and prey item; Partial $\chi^{2}=7.73, \mathrm{df}=2, P=0.02$; Table 1). A high proportion of seal on Chatfield Island in 2001 caused the 3-way association (Table 1). Accordingly, when we excluded seal from log-linear analysis, the association between location, age class of wolf, and prey item was not significant (Partial $\chi^{2}=0.20$, df $=1, P=0.65$ ). We then found, similar to other areas and years, that pups consumed a significantly smaller proportion of adult deer than did adult wolves at both locations $\left(\right.$ Partial $\left.\chi^{2}=17.91, \mathrm{df}=1, P<0.001\right)$.

\section{Discussion}

A large body of literature exists regarding wolf diet but it primarily addresses spatial and temporal patterns (Paquet and Carbyn 2003; Peterson and Cuicci 2003) and not other aspects of intrapopulation variability. Relatively little dietary information exists in the context of raising young. Exceptions include two studies that found significant differences in the diet of adult wolves between den sites and nearby areas (Theberge et al. 1978; Meleshko 1986). Neither study, however, differentiated between pup and adult diet as we do here.

Herein, we show that juvenile and adult wolves from two coastal islands have similar niches at the prey species level, as they have similar dietary breadth and moderate overlap. These results show that adult wolves provide pups with food items similar to themselves and are not hunting distinct prey species for pups. At a finer resolution, however, we show that diets differ between pups and adults, which we infer as evidence for selective provisioning. Controlling for location and year effects, our log-linear results showed that pups were supplied a smaller proportion of adult deer than consumed by adults.

The difference we detected could be influenced by limitations in prey identification methods. Results of our precision test show a possible directional bias in categorization of deer age class towards fawns. The direction (or magnitude) of the difference between pup and adult diet, however, would not be affected and thus we consider this possible bias unimportant. Regardless, this demonstrates the importance of testing for, and reporting on, precision (and accuracy), which is extremely rare in dietary studies on wolves or other taxa (cf. Fritts and Mech 1981; Cuicci et al. 1996; Darimont et al. 2004). 
TABLE 2. Dietary breadth and overlap as inferred by faecal collection from den sites of pup and adult Gray Wolves, coastal British Columbia, summers 2001 and 2002.

\begin{tabular}{|c|c|c|c|c|c|}
\hline & \multicolumn{2}{|c|}{$\begin{array}{l}\text { Chatfield } \\
\text { Island }\end{array}$} & \multicolumn{2}{|c|}{$\begin{array}{c}\text { Yeo } \\
\text { Island }\end{array}$} & \multirow[t]{2}{*}{ Average } \\
\hline & 2001 & 2002 & 2001 & 2002 & \\
\hline \multicolumn{6}{|l|}{ Dietary breadth } \\
\hline Pup & 0.37 & 0.87 & 0.21 & 0.35 & 0.45 \\
\hline Adult & 0.41 & 0.95 & 0.27 & 0.32 & 0.49 \\
\hline \multicolumn{6}{|l|}{ Dietary overlap } \\
\hline Percent Overlap & 79 & 79 & 72 & 86 & 79 \\
\hline Horn's Index & 0.95 & 0.97 & 0.93 & 0.98 & 0.96 \\
\hline
\end{tabular}

Selective provisioning occurs if diets of providing adults and altricial young differ, and evolves when the behavior is advantageous for reproduction or survival. Well-described in birds (e.g., Martin 1987; Wright et al. 1998), we suspect this behaviour is common in wolves and potentially other mammals. Although we have no data to indicate why adult wolves selectively provision pups, several "logistic" and adaptive explanations are plausible.

While likely rooted in adaptive value, provisioning strategies probably are shaped further by logistic or environmental factors that affect the relative benefits and costs of providing care to young. First, adults may selectively provision resources such as whole fawns or portions of fawns because they are easy to transport to young (e.g., Molsher et al. 2000). Ease of transport may be particularly important when pups are old enough to consume solid prey items. Other important factors affecting wolf foraging, and subsequent provisioning, are spatial and temporal variation in prey abundance (e.g., Theberge et al. 1978; Meleshko 1986), which would then interact with how pack members divide the provisioning labour. Contributions to young by each member would depend on age, experience, hunting habits, social status, and genetic relatedness to offspring (Mech et al. 1999). For example, pup diets could be biased if individual wolves such as the mother or father target fawn and provision at a higher frequency than other pack members.

Among several adaptive hypotheses, we speculate that parents may base provisioning decisions on nutritional requirements of developing young. For example, protein is important for growing animals (Robbins 1993) and may be particularly important in large carnivores such as wolves (Lauer et al. 1969). If protein content drives provisioning, then a greater proportion of high-protein resources would be expected in the diet of young wolves. Based on published values, there is no difference in protein content between age classes of deer (Percent body weight $=20.3$ for both fawn $[n=7]$, and adult $[n=16]$ White-tailed Deer, $O$. virginianus; means calculated from Robbins 1973). This suggests that protein is not a driving factor in provisioning we observed.
Differences in body fat among prey might contribute to adaptive provisioning behaviour. Body mass, which is often associated with consumption of fatty resources in large mammals, is important for survivorship for both providers and offspring (Derocher and Stirling 1996). Of major prey items in this study, seal had the highest fat content (percent body weight $=23.6[n=35]$, Harbour Seal; Coltman et al. 1998) followed by adult deer (Percent body weight $=12.8,[n=16]$, Whitetailed Deer; mean calculated from Robbins 1973) fawn (percent body weight $=3.1[n=7]$, White-tailed Deer; mean calculated from Robbins 1973). Although pups consumed more high-fat prey items (seal) than adult wolves on Chatfield Island in 2001, they consumed less high-fat prey items (adult deer) than adult wolves at all locations. This suggests that adult wolves may provide their young with high-fat food only when there is an abundance of high-fat prey items. Otherwise, it is possible that adults may be selectively retaining prey items of higher fat content, which may represent a benefit controlled by provisioners in what potentially is a parent-offspring (or in this case, provider-receiver) conflict (Trivers 1974).

Wolves may provision according to potential parasite load in prey, which may provide the best adaptive explanation for the pattern we observed. As ungulates and other animals age, their parasite burden often increases (Crooks et al. 2001). Increasing prevalence of parasitic infection with age has been found in Whitetailed Deer (Bogaczyk et al. 1993), Marsh Deer (Blastocerms dichotomus), and Pampas Deer (Ozotocerus bezarticus; Ferreira et al. 1997). Although we could not find similar studies on black-tailed deer, we postulate that comparable disease dynamics occur in this species.

Many studies have shown that parasites are important in parental care strategies (Christe et al. 1994; Merilä and Allander 1995; Moreno et al. 1999; Tripet et al. 2002). Young animals have naive immune systems, as they have not been exposed to a wide variety of pathogens (Hutchings et al. 2002). Low levels of exposure to pathogens can help young develop immunity but high levels can have severe consequences on survival. Therefore, gradual introduction of pathogens 
to young animals by providers is likely important, which an early diet biased towards fawns may achieve.

Avoiding excessive exposure to parasites may be particularly important in wolves, given their life history. Wolves are k-selected organisms, investing considerably in relatively few offspring. Furthermore, populations demonstrate a type I survivorship curve. Survival in pups, although not well studied, is thought to be typically lower compared with resident adults (Fuller et al. 2003). Pup mortality is often related to or influenced by diseases, many of which exploit prey as intermediate hosts (Kreeger 2003).

Future studies could address logistic and adaptive hypotheses we have presented herein and their possible interaction. In summary, we suggest that selective provisioning strategies should now be considered among the behaviours of wolves and one that contributes to maximizing lifetime reproductive output.

\section{Acknowledgments}

This study took place in Heiltsuk Traditional Territory, and we thank them for their support and involvement. We are grateful to the Raincoast Conservation Society for financial and logistical support as well as to A., J., and R. Bryan, H. Down, J. Gordon-Walker, J. Havelaar, D. Klinka, I. and K. McAllister, G. Pfleuger, M. Price, R. Ring, M. Spoljaric, C. Starr, and $\mathrm{N}$. Winchester. The McCaw Foundation, National Geographic Society, Wilburforce, Vancouver Foundation, World Wildlife Fund Canada, and private donors kindly provided funding. While preparing the manuscript, CTD was supported by a Natural Sciences and Engineering Research Council (NSERC) - Industrial Postgraduate Scholarship.

\section{Documents Cited (marked* in text)}

Darimont, C. T., and P. C. Paquet. 2000. The Gray Wolves (Canis lupus) of British Columbia's coastal rainforests: findings from year 2000 pilot study and conservation assessment. Prepared for the Raincoast Conservation Society. Victoria, British Columbia. Available at www.rain coast.org.

\section{Literature Cited}

Adorjan, A. A., and G. B. Kolenosky. 1969. A manual for the identification of hairs of selected Ontario mammals. Ontario Department of Lands and Forests Research Report (Wildlife) 90: 1-64.

Angerbjörn, A., M. Tannerfeldt, and S. Erlinge. 1999. Predator-prey relationships: Arctic Foxes and Lemmings. Journal of Animal Ecology 68: 34-39.

Bogaczyk, B. A., W. B. Krohn, and H. C. Gibbs. 1993. Factors affecting Parelaphostrongylus tenuis in a Whitetailed Deer (Odocoileus virginianus) from Maine. Journal of Wildlife Diseases 29: 266-272.

Bolnick, D. I., R. Svanbäck, J. A. Fordyce, L. H. Yang, J. M. Davis, C. D. Hulsey, and M. L. Forister. 2003. The ecology of individuals: Incidence and implications of individual specialization. The American Naturalist 161: 128.
Christe, P., A. Oppliger, and H. Richner. 1994. Ectoparasites affect choice and use of roost sites in the Great Tit, Parus major. Animal Behaviour 47: 595-898.

Coltman, D. W., W. D. Bowen, S. J. Iverson, and D. J. Boness. 1998. The energetics of male reproduction in an aquatically mating pinniped, the Harbour Seal (Phoca vitulina). Physiological Zoology 71: 387-399.

Crooks, K. R., C. A. Scott, and D. H. Van Vuren. 2001. Exotic disease and an insular endemic carnivore, the Island Fox. Biological Conservation 98: 55-60.

Cuicci, P., L. Boitani, and A. L. Lovaas. 1996. A comparison of scat-analysis methods to assess the diet of the Wolf (Canis lupus). Wildlife Biology 2: 37-48.

Darimont, C. T., and P. C. Paquet. 2002. The Gray Wolves (Canis lupus) of British Columbia's Central and North Coast: distribution and conservation assessment. Canadian Field-Naturalist 116: 416-422.

Darimont, C. T., M. H. H. Price, N. N. Winchester, J. Gordon-Walker, and P. C. Paquet. 2004. Predators in natural fragments: foraging ecology of wolves in British Columbia's Central and North Coast archipelago. Journal of Biogeography 31: 1864-1874.

Derocher, A. E., and I. Stirling. 1996. Aspects of survival in juvenile polar bears. Canadian Journal of Zoology 74: 1246-1252.

Elmhagen, B., M. Tannerfeldt, and A. Angerbjörn. 2002. Food-niche overlap between Arctic and Red Foxes. Canadian Journal of Zoology 80: 1274-1285.

Ferreira, R. A., J. R. Mineo, J. M. Duarte, D. A. O. Silva, and J. H. Patarroyo. 1997. Toxoplasmosis in naturally affected deer from Brazil. Journal of Wildlife Diseases 33: 896-899.

Fritts, S. H., and L. D. Mech. 1981. Dynamics, movements, and feeding ecology of a newly protected wolf population in northwestern Minnesota. Wildlife Monographs (80). The Wildlife Society, Bethesda, Maryland.

Fuller, T. K., L. D. Mech, and J. F. Cochrane. 2003. Wolf population dynamics. Pages 161-191 in Wolves: behaviour, ecology and conservation. Edited by L. D. Mech and L. Boitani. The University of Chicago Press, Chicago, Illinois.

Horn, H. S. 1966. Measurement of overlap in comparative ecological studies. American Naturalist 100: 419-424.

Hurlbert, S. H. 1978. The measurement of niche overlap and some relatives. Ecology 59: 67-77.

Hutchings, M. R., J. M. Milner, I. J. Gordon, I Kryziakus, and F. Jackson. 2002. Grazing decisions of Soay Sheep, Ovis aries, on St Kilda: a consequence of parasite distribution? Oikos 96: 235-244.

Krebs, C. J. 1999. Ecological methodology. $2^{\text {nd }}$ edition. Benjamin/Cummings, Menlo Park, California.

Krebs, J. R., and M. A. Avery. 1984. Chick growth and prey quality in the European Bee-eater (Merops apiaster). Oecologia 64: 363-368.

Kreeger, T. J. 2003. The internal wolf: physiology, pathology, and pharmacology. Chapter 7 in Wolves: behaviour, ecology and conservation. Edited by L. D. Mech and L. Boitani. University of Chicago Press, Chicago, Illinois .

Lauer, B. H., E. Kuyt, and B. E. Baker. 1969. Wolf milk. I. Arctic Wolf (Canis lupus arctos) and husky milk: gross composition and fatty acid constitution. Canadian Journal of Zoology 47: 99-102.

Markman, S., B. Pinshow, and J. Wright. 2002. The manipulation of food resources reveals sex-specific trade-offs between parental self-feeding and offspring care. Proceed- 
ings of the Royal Society of London Series B 269: 19311938.

Martin, T. E. 1987. Food as a limit on breeding birds: a life history perspective. Annual Review of Ecology and Systematics 18: 453-487.

Mayer, W. V. 1952. The hair of California mammals with keys to the dorsal guard hairs of California mammals. American Midland Naturalist 48: 480-512.

Mech, L. D., P. C. Wolf, and J. M. Packard. 1999. Regurgitative food transfer among wild Wolves. Canadian Journal of Zoology 77: 1192-1195.

Meleshko, D. W. 1986. Feeding habits of sympatric canids in an area of moderate ungulate density. MSc. thesis, University of Alberta, Edmonton, Alberta, Canada.

Merilä, J., and K. Allander. 1995. Do Great Tits (Parus major) prefer ectoparasite-free roost sites? An experiment. Ethology 99: 53-60.

Molsher, R. L., E. J. Gifford, and J. C. McIlroy. 2000. Temporal, spatial, and individual variation in the diet of Red Foxes (Vulpes vulpes) in central New South Wales. Wildlife Research 27: 593-601.

Moreno, J., J. J. Sanz, and E. Arreiro. 1999. Reproductive effort and T-lymphocyte cell-mediated immunocompetence in female pied flycatchers Ficedula hypoleuca. Proceedings of the Royal Society of London B 266: 1105-1109.

Paquet, P. C., and L. N. Carbyn. 2003. Gray Wolves. Pages 482-510 in Mammals of North America. Revised $2^{\text {nd }}$ edition. Edited by G. Feldhamer and B. Thompson. Johns Hopkins University Press, Baltimore, Maryland.

Peterson, R. O., and P. Cuicci. The wolf as a carnivore. Pages 104-130 in Wolves: behaviour, ecology and conservation. Edited by L. D. Mech and L. Boitani. The University of Chicago Press, Chicago, Illinois.

Polis, G. A. 1984. Age structure component of niche width and intraspecific resource partitioning: can age groups function as ecological species? American Naturalist 123: 541564.
Robbins, C. T. 1973. The biological basis for determining carrying capacity. $\mathrm{PhD}$ dissertation, Cornell University, New York.

Robbins, C. T. 1993. Wildlife feeding and nutrition. $2^{\text {nd }}$ edition. Academic Press, San Diego, California.

Scott, B. M., and D. M. Shackleton. 1979. Food habits of two Vancouver Island wolf packs: a preliminary study. Canadian Journal of Zoology 58: 1203-1207.

Shackleton, D. 1999. Hoofed mammals of British Columbia. Royal British Columbia Museum handbook. UBC Press, Vancouver, British Columbia.

Schoener, T. W. 1970. Non-synchronous spatial overlap of lizards in patchy habitats. Ecology 51: 408-418.

Spaulding, R., P. R. Krausman, and W. B. Ballard. 2000. Observer bias and analysis of Gray Wolf diets from scats. Wildlife Society Bulletin 28: 947-950.

Theberge, J. B., S. M. Oosenbrug, and D. H. Pimlott. 1978. Site and seasonal variation in food of wolves. Algonquin Park, Ontario. Canadian Field-Naturalist 92: 91-94.

Tripet, F., M. Glaser, and H. Richner. 2002. Behavioural responses to ectoparasites: time-budget adjustments and what matters to Blue Tits Parus caeruleus infested by fleas. Ibis 144: 461-469.

Trivers, R. L. 1974. Parent-offspring conflict. American Zoologist 14: 249-264.

Weaver, J. L., and S. H. Fritts. 1979. Comparison of coyote and wolf scat diameters. Journal of Wildlife Management 43: 786-788.

Wright, J., C. Both, P. A. Cotton, and D. Bryant. 1998. Quality vs. quantity: energetic and nutritional trade-offs in parental provisioning strategies. Journal of Animal Ecology 67: 620-634.

Received 1 March 2005

Accepted 18 November 2005 